\title{
Trend of Certified Forest Products (CFPs) Market in Japanese
}

\section{Construction Industries}

\author{
Sakamoto, $\mathrm{T}$ \\ Department of Forest and Biomaterials Science, Graduate School of Agriculture, Kyoto University \\ 606-8502 Kyoto, Japan \\ Tel: 81-75-753-6440Ｅ-mail: Tomomi.Sakamoto.Jasc60@gmail.com
}

Shiba, M.

Field Science Education and Research Center, Kyoto University

606-8502 Kyoto, Japan

Tel: 771-77-0321 E-mail: mshiba@kais.kyoto-u-ac.jp

Pakhriazad H.Z. (Corresponding author)

Department of Forest Management, Universiti Putra Malaysia

43400 Serdang, Selangor, Malaysia

Tel: 80-5341-7019Ｅ-mail: asato40@hotmail.com

Schaller, M.

Center of Life and Food Science, Weihenstephan Technische Universitaet Muenchen

Am Hochanger 13, D - 85354 Freising, Germany

Tel. 8161-714632Ｅ-mail: Schaller@tum.de13

\begin{abstract}
Japan grants the largest number of forest Chain of Custody (CoC) certification compared to Europe and North America. At present, major wood and paper industries constitute most of the certificate holders. The pattern of wood utilization by construction industry will strongly affects the future market of certified forest products (CFPs) in Japan. The study examines the current status and prospect of CFPs market in the Japanese construction industry. A questionnaire survey was distributed to 203 non-certified construction companies in Tokyo, Osaka, Aichi prefectures and to $39 \mathrm{CoC}$ certified firms of Japan Forest Stewardship Council (FSC), Programme for the Endorsement of Forest Certification Schemes (PEFC) and Sustainable Green Ecosystem Council (SGEC) certification bodies. Companies which have been certified had earlier established wood supply chain before obtained the certificates. Study revealed that certified companies emphasized more on environmental aspects when purchasing wood materials compared to non-certified ones. A total of $67 \%$ of non-certified companies purchased or intended to purchase environment-friendly wood products (EWP). Others were only interested in recycled wood products which are not fall under the CFPs categories. Most companies do not obtain CFPs because of insufficient knowledge about forest certification schemes. According to the decision tree analysis, companies which established earlier supply chain checking system have stronger decision over wood procurement, and therefore, have higher tendency to obtain certificates.
\end{abstract}

Keywords: Chain of custody, Certified forest products, Construction industries, Decision tree analysis

\section{Introduction}

Forest certification is an instrument to ensure that forests are managed in accordance to a standard appropriate to the environmental, socially beneficial, and economically viable. For a producer to make claims of forest certification in association with its products in the form of a product label, the chain of custody $(\mathrm{CoC})$ must be established and certified (Estey, 2000). Products from certified forests can be verified through a CoC system that provides the ability to track them from the forest to the final products (Nussbaum and Shimura, 2005). Even though rate of certified forest area has been declined in 2006, the CoC grew by $50 \%$ in 2007, attaining 12,600 
certificates worldwide in 2008 (Kraxner et al., 2008). The CoC certificates issued internationally, with much of the rest are Germany, France, and Japan (Oliver and Kraxner, 2009). Japan is one of the world's leading importers of wood products and depends on $80 \%$ of imported wood. As the demand for certified products increased in Japan, certification is expected to raise in the export countries (WWF, 2000). The notable market characteristic of Japan was that paper product companies outnumbered wood product companies in $\mathrm{CoC}$ certificates. There are three schemes currently operating in Japan, namely; the Forest Stewardship Council (FSC), the Sustainable Green Ecosystem Council (SGEC) and the Programme for the Endorsement of Forest Certification Schemes (PEFC). The FSC and PEFC are international certification programs and SGEC is a national scheme (Owari and Sawanobori, 2008).

The green building systems, which operates globally in the construction sector growing as worldwide movement (Irland, 2007). In the United States and Europe green building systems and green procurement policies, which require the utilization of certified wood are helping to promote certification in the construction market. In Japan, the system has been developed and demand for certified wood is certain to grow (Bowyer, 2008). The future CFPs market driven in Japan constructions sector highly depends on the builders decisions. Only a few construction companies were certified, even though the industry has significant impact on the CFPs products market. The construction industry consumed $80 \%$ of the total lumber shipment and wooden building accounted 47\% of new housing construction in 2008 (Forestry Agency, 2009). The study was conducted to examine customer perceptions towards non-certified companies about CFPs and to identify factors that motivate them to obtain the certificate.

\section{Materials and Methods}

In this study certificates directories by Japan Forest Stewardship Council (FSC), Programme for the Endorsement of Forest Certification Schemes (PEFC) and Sustainable Green Ecosystem Council (SGEC) were used to analyze $\mathrm{CoC}$ certificate holders and their products. A questionnaire survey was conducted to examine the construction companies' attitudes toward CFPs. A total of 865 construction companies located in Tokyo, Osaka, and Aichi prefecture registered to Quality Builders Club, Japan Wooden House Industry Association, Japan $2 \times 4$ Home Builders Association and General Constructions Association of Japan were selected as respondents. Each association consists of different types of companies. The Quality Builders Club are local builders which were certified through their management training program. The Japan Wooden House Industry Association are the builders, building material suppliers and architects of wooden houses. The Japan $2 \times 4$ Home Builders Association is the incorporated organization of wood frame building contractors, building material suppliers and architects. The General Constructions Association of Japan consists of 23,000 registered general contractors nationwide. Our surveys range from small home builders to large general contractors. Of the 781 companies targeted, only two companies obtained a CoC certificate. A survey was also conducted to FSC, PEFC or SGEC certified construction companies nationwide and a total of 84 questionnaires were distributed. The questionnaire consists of 3 different sections with 32 questions. In the first section respondents were asked regarding the importance of purchasing certified wood materials, their consciousness and their decision to purchased environment-friendly wood products (EWPs) in future. The second section gathered information on wood purchasing such as decision makers, type of suppliers and wood supply chain. In June 2009 the questionnaire was sent to 865 respondents. A total of 242 respondent replied with an adjusted response rate of $28.3 \%(242 / 855)$. Of the 242 respondents, 203 entities were not certified and 39 had obtained a CoC certificates. Non-certified respondents involve in various type of constructions and customers (Table 1). Certified respondents of smaller companies constituted a greater portion than larger ones, biased toward companies and individuals engaged on wooden construction work.

Collected data were analyzed using the Excel Statistics 2008 and WEKA3-3-6 (Waikato Environment for Knowledge Analysis). The percentage of respondents with each question was computed and a chi-square test was used to measure significant difference between certified and non-certified companies. Based on the point which showed significant difference, we make a decision tree presenting the factors affecting company's decision on certification. Many data mining methods generate decision trees whose leaves are classifications and whose branches are conjunctions of features that lead to those classifications (Menzies and $\mathrm{Hu}, 2003$ ). Decision tree algorithms begin with a set of cases and create a tree data structure that can be used to classify new cases. Each case is described by a set of attributes which have numeric or symbolic values. Decision trees are an output of the procedures and there are many algorithms available for constructing decision trees (Ekasingh and Ngamsomsuke, 2009). Data mining procedures are essentially machine learning techniques for inducing domain models or analyzing datasets. The algorithm used in this study is the J4.8 which slightly improved C.4.5 Revision 8 (Witten and Frank, 2000). Decision trees are simple classifier and easy to interpret because of its 
clear hierarchy chart with nodes and branches (Kingsford et. al., 2008; Furuta, 2007).

\section{Results}

\subsection{CoC certification in Japan}

By the end of 2008, United States and United Kingdom accounted for 31\% of all FSC and PEFC. When certification was first introduced in Japan in 2000 there is no demand for CFPs. However, the certified companies drastically increased to 1,300 in 2009. The FSC has dominated CoC certification schemes in Japan with $70 \%$ of the certificates issued. At the early stage, certification mainly directed at wood and paper products, which comprised about $81 \%$ in 2009 (Owari and Sawanobori, 2007) (Figure 1). In Japan, certified paper manufacturers outnumbered the wood products companies. Japanese paper companies obtained FSC forest certification through their overseas plantation forests. They imported certified pulp for paper productions in Japan. Based on the system, all their stakeholders in the paper business will be certified (Sakamoto and Shiba, 2009).

The SGEC was established in 2004 to improve Japanese forests and forestry related activities by developing a forest certification system suitable for Japan. SGEC standards were developed based on the concept of sustainable forest management practices. It reflects Japan's situation while maintaining international requirements (Mashita, 2004). Forested areas certified by SGEC are 784,282 hectares (ha) surpassed the FSC with a total of 282,982 ha. Most of the companies certified by SGEC were domestic wood products companies. The PEFC certification system was introduced in Japan in 2004. There are no PEFC certified forests in Japan. Therefore, raw materials for certified products are totally imported. Two-thirds of PEFC - CoC certificate holders were paper manufacturers and wood products companies. Recently, PEFC certified companies have increased and more certified timber products were imported.

\subsection{Non-certified companies' perception towards CFPs}

This section discussed the current situation of CFPs market in the construction sector based on the data from 203 non-certified respondents. A total of 192 (95\%) respondents addressed on environmental related issues. As a part of environment-friendly building activities, a total of 139 companies (69\%) employed environmental-friendly building materials, 105 companies (52\%) purchased environment-friendly wood products (EWPs) and 31 (15\%) plan to use EWPs in future (Figure 2). The EWPs were used for a wide range of building components such as decorative and construction material, fittings, exterior or civil engineering material. Result shows that 136 (67\%) respondents reflect their positive attitude toward EWPs and $58(29 \%)$ companies has no intention to purchase EWPs. Study shows that suppliers, quantity and specification were most important criteria followed by subsidies or preferential treatments for EWPs. A total of 105 respondents used EWPs procured recycled wood $(50 \%)$, thinned wood (48\%), $11(10 \%)$ utilized CFPs while other $20(19 \%)$ had intention to do so in future. A total of 31 respondents planning to purchase EWPs intended to use recycled wood (60\%), thinned wood (55\%) and $5(16 \%)$ plan to get CFPs.

The Government of Japan has introduced new methods for verifying legality and sustainability of wood products. They decided to promote verified products for procurement of all ministries and agencies, independent administrative institutions and special legal entities. The Basic Policy on Promoting Green Purchasing of the Law Concerning the Promotion of Procurement of Eco-friendly Goods and Services by the State and Other Entities (Law of Green Purchasing) was amended by the Japan Forestry Agency in 2006. The designated procurement items listed in this law includes materials for public works. The Japan Sustainable Building Consortium has developed the Comprehensive Assessment System for Building Environmental Efficiency (CASBEE), which allows a higher rating in using wood from thinning forests, sustainably managed forests and domestic softwood. Both laws verify legal and sustainable resources according to the Guideline for Verification on Legality and Sustainability of Wood and Wood Products formulated by the Japan Forestry Agency. In 2006, 5 Non Governmental Organizations in Japan published a joint declaration requiring all administrative agencies and companies dealing with various wood products and buildings to use CFPs (Figure 2). Out of 203 selected companies, only $20(10 \%)$ conscious with forest certification and $81(41 \%)$ had no idea about the schemes.

\subsection{Characteristics of certified companies}

This section discussed the characteristics of certified companies and non-certified companies. Most companies recognized the slogan of pro-environment company activity, pro-environment construction work, using pro-environment building materials and using EWPs (Figure 3). Results shows that there is a significant difference in the EWPs interpretation between certified and non-certified companies $(\mathrm{p}<0.05)$. The reason for both companies purchased or planned to purchase the EWPs is to improve their corporate image (Figure 4). 
There were significant differences in the proportion selecting "enterprise differentiation", "a part of corporate social responsible", "customer request" and "compliance with law" between certified and non-certified companies $(\mathrm{p}<0.01)$. Certified companies mainly focused on "enterprise differentiation" while non-certified ones had interests in EWPs as a result of "customer request". Other reason included that their business partner had obtained certification (Figure 4). Result showed that there were significant difference with regard to priorities of wood procurement $(\mathrm{p}<0.01)$. Non-certified companies emphasized on practical aspects such as "price", "specification", "quality" and "stable supply", which combined $90 \%$ of both first and second priority (Figure 5). Certified companies also concerned on environmental aspects such as "legality", "domestic", "originated from a sustainable-managed forest" and "procurement from environmentally and socially responsible supplier", which combined for more than $40 \%$ of both first and second priorities. Our study revealed that many certified companies had established the customers supply chain earlier before they obtained a certificate (Figure 6) and showed significant difference from non-certified companies $(\mathrm{p}<0.01)$.

\subsection{Decision tree model for CoC certification}

The section discussed the decision tree of a model company with $\mathrm{CoC}$ certification. The data set is divided into sub-samples through building decision tree model. The original sample is referred to the root node and each of the sub-samples is called a node. The partitioning is done based on one of the independent variables known as the splitting attribute. Branches are drawn for different values of this splitting attribute. Each instance in the root node is sent down one of the branches into one of the nodes depending on its value for the splitting attribute. The choice of splitting attribute is conducted by picking the attribute that will partition the original sample into sub-samples that are as homogenous as possible in relation to the class variable. Each node is partitioned by considering only the cases in that node and new nodes are created from instances in that node alone. This process is repeated for each node until some stopping-rule is violated. When this occured the node is not further partitioned and this node is referred to as leaf node. The whole process is terminated when there are only leaf nodes left. Our preliminary studies found that there were differences in the perception about EWPs between certified and non-certified companies; First, the priorities of wood procurement and second the extent to which they monitor the wood supply chain. Thus, we selected three explaining variables "self-discretion", "customer" and "check system", which considered affecting these differences. Figure 7 shows the results of decision tree analysis. Using the 10-fold cross-validation method in WEKA, the percentage of correctly classified instances was $87.6 \%$ (Table 2).

Most important variable for classification was "check system" to ensure the existence of wood supply chain. For certified companies, there is a possibility of having a check system after certification. Without check system the company was classified as "non-certified" (91.2\% accuracy). Companies with a check system will proceed down to the node of "self-discretion". Respondents were asked regarding the top 3 decision-makers for wood procurement and "self-discretion" node branched according to the right of self-determination positioned. Companies which answered that they are prominent on decision making were classified as "certified" $(74.1 \%$ accuracy). Most of the certified firms tended to have stronger power of decision while non-certified were among customers, architects, and sub-contractors. Many certified companies answered that there were no second and third party in the process, which meant most certified companies possessed their own discretion for making decision. At this stage a total of 238 of 242 respondents have already classified. The other 4 companies were classified according to main customer type (customer accounted for majority). When two type of customer accounted each for $50 \%$ or no customer having a majority, then the company is labeled "mix". Companies having another firm as customer were classified as "certified" ( $93.9 \%$ accuracy). The number of instances was only 4.

\section{Discussion}

Environmental issues are important for construction companies in Japan. There were a few non-certified companies purchased or intended to purchase CFPs but could not selling them as labeled products without having a certificate. Japanese government launched various campaigns to promote thinning and consumption of thinned wood for greenhouse gas reduction, soil and water conservation and reactivation of domestic forests and forestry related activities. In the United States, many green building professionals were familiar with FSC and green/LEED building project but in Japan certified companies embracing environmental-friendly building activities still not well recognized. Larger companies are more likely to be CoC certified than smaller ones (Vidal et. al., 2003). One reason is on the relationships between small scale contractors with large scale contractors. Potential supply of CFPs is still low since large building material suppliers have not recognized forest certification (Tanaka, 2008). Certified companies considered implementing EWPs not just as reaction to laws or customer requests, but also as important strategy. Certified companies recognize the importance of EWPs and 
emphasis more on environmental aspects when purchasing wood materials. According to the decision tree analysis, companies which establish a supply chain checking system in advance have stronger decision power over wood procurement and could motivate them to obtain a certificate. Furthermore, companies with a centralized procurement will be able to monitor their suppliers to purchase certified products.

It is effective for certifying organization to focus on the companies that highly committed to utilize wide range of wood procurement such as construction industries. It is to develop a supply chain check system and to enhance self-discretion over wood procurement to promote $\mathrm{CoC}$ certification in future. Procurement personnel need to be trained in order to enhance the certification process. Customer interest is an important factor prompting non-certified companies to procure EWPs. Therefore, the CFPs suppliers should make an effort to meet cooperate needs for variety and quantity as well as price and quality.

\section{Conclusion}

The CFPs market in the construction industry is still considered small in Japan. At present, neither policy nor schemes for promoting CFPs has shown remarkable effects. However, demand for CFPs is increasing as a result of public awareness toward EWPs. A private forest in Japan has obtained SGEC certification and has integrated with other companies such as saw millers, lumber dealers, building material suppliers for a CoC group certificates. Another company received PEFC certificate for their overseas factories and a few local governments in Japan has subsidized housing constructed with CFPs. The current situation of Japan CFPs market and the characteristics of certified companies presented in this study would help policy makers and certifying organization to promote $\mathrm{CoC}$ certification in the construction industry. Factors such as characteristics of forest areas, differences in domestic rules and regulations are considered important, which may influence the company perceptions about CFPs. Thus, future research should focus on companies established throughout the country, which will not only make the local conditions analyzable but also represent more accurate and overall condition of the Japanese construction industries.

\section{Acknowledgements}

We would like to thank Hayami,T., Akito K., Takeo, G., Homma, Kenji T., Hiroyuki, O., Syuichi T. and Hitoshi M. for helpful comments. We also would like to thank all respondents for their sincere cooperation and kind assistant.

\section{References}

Araya, A. (2004). Timber trade and forest certification. In: Sakai, M. Forest Policy Study. J-FIC, Tokyo, 53-269.

Bowyer, L. (2008). The green movement and the forest products industry. Journal of Forest Production, 58, 6-13.

Ekasingh, B., \& Ngamsomsuke, K. (2009). Searching for simplified farmers' crop choice models for integrated watershed management in Thailand: A data mining approach. Environment Model Software, 24, 1373-1380.

Estey, S. (2000). Chain of custody as an impediment to certification. In: Vogt, K., Larson, B., Gordon, J., Vogt, D., Fanzeres, A. Forest certification: roots, issues, challenges, and benefits. CRC Press, Florida, 285-291.

Forestry Agency, Japan. (2009). Forest and forestry white paper. Japan Forestry Association, Tokyo.

Furuta, K. (2007). The structure of motives for educational expenditures: Decision tree analysis of attitudes toward education. Journal of Education Sociology, 80, 207-225.

Kingsford, C., \& Salzberg, S. (2008). What are decision trees? Natural Biotechnology, 26, 1011-1013.

Irland, L. (2007). Developing markets for certified wood products, greening the supply chain for construction materials, Journal of Industrial Ecology, 11: 201-216.

Mashita, M. (2004). Reviving forests, forestry, and mountain villages with "Sustainable Green Ecosystem”. In: National forestry extension association. The forest certification, forestry and the industry of forest and wooden products (Japanese version). National Forestry Extension Association. Tokyo, Japan, 114-145.

Nussbaum, R., \& Shimura, M. (2005). The forest certification handbook, $2^{\text {nd }}$ editions. Earthscan, London.

Oliver, R., \& Kraxner, F. (2009). Forest certification challenged by climate change and illegal logging concerns: Certified forest products markets. In: UNECE/FAO, Forest products annual market review 2008-2009. Timber and forest study paper 24. United Nations, New York, 111-123.

Owari T., \& Sawanobori, Y. (2007). Analysis of the certified forest products market in Japan. Holz. Roh. Werkst, $65,113-120$. 
Owari T., \& Sawanobori, Y. (2008). Market benefits of chain of custody certification, Perspectives of Japanese suppliers. In: Sasaki, N., Yoshimoto, A. Forest Resource Management and Mathematical Modeling-FORMATH KOBE 2007-, Japan Society of Forest Planning Press. Utsunomiya, Japan, 121-132.

Sakamoto, T., \& Shiba, M. (2009). The development of CoC certificate in Japan: Focus on FSC-CoC Certificate in paper and pulp industry. Applied Forest Science, 18 (1), 1-7.

Tanaka, M. (2008). A Study on the ecological products of building industry based on questionnaire results from companies. Journal of Human Environmental Studies, 7, 103-127.

Vidal, N., Kozak, R., \& Cohen, D. (2003). Chain of custody certification: An assessment of the North American sold wood sector. Forest Policy and Economics, 7, 345-355.

Werndle, L., Brown, N., \& Packer, M. (2006). Barriers to certified timber and paper up take in the construction and paper industries in the United Kingdom. Journal of Corporate Social Responsibility and Environmental Management, 13, 121-134.

Witten, I.H., \& Frank, E. (2000). WEKA Machine learning algorithms in java: Data mining. Practical machine learning tools and techniques with java implementation. Morgan Kaufmann, San Francisco.

WWF. (2000). Certification. A future for the world's forests -. Forests for life campaign. Branksome House, UK.

\section{Notes}

Note 1. (Table 1): Civil engineering work accounts for more than $80 \%$ of total sales. ${ }^{2}$ Civil engineering work accounts for less than $20 \%$ and non-wooden construction work constitutes a greater portion than wooden one. ${ }^{3}$ Civil engineering work accounts for less than $20 \%$ and wooden construction work constitutes a greater portion than non-wooden one. ${ }^{4}$ Each construction type constitutes different portion from $1-3$. ${ }^{5}$ Customers account the same share.

Note 2. (Table 2): When there are missing values, an instance is divided into some leaves. As a result, the number of instances of each leave becomes decimal.

Table 1. Respondents profile by sectors

\begin{tabular}{|c|c|c|c|c|}
\hline \multirow[t]{2}{*}{ Attributes } & \multicolumn{2}{|c|}{$\begin{array}{l}\text { Non-certified companies } \\
\qquad(n=203)\end{array}$} & \multicolumn{2}{|c|}{ Certified companies $(n=39)$} \\
\hline & $\mathrm{n}$ & $\%$ & $\mathrm{n}$ & $\%$ \\
\hline \multicolumn{5}{|l|}{ 1. Main construction type } \\
\hline Civil engineering $^{1}$ & 19 & 9.4 & 0 & 0.0 \\
\hline Non-wooden & 63 & 31.0 & 3 & 7.7 \\
\hline \multicolumn{5}{|l|}{ construction $^{2}$} \\
\hline Wooden construction $^{3}$ & 53 & 26.1 & 26 & 66.7 \\
\hline General construction $^{4}$ & 52 & 25.6 & 5 & 12.8 \\
\hline others & 10 & 4.9 & 2 & 5.1 \\
\hline No answer & 6 & 3.0 & 3 & 7.7 \\
\hline \multicolumn{5}{|l|}{ 2. Number of employees } \\
\hline $1-9$ & 39 & 19.2 & 12 & 30.8 \\
\hline $10-49$ & 82 & 40.4 & 14 & 35.9 \\
\hline $50-99$ & 21 & 10.3 & 5 & 12.8 \\
\hline $100-499$ & 43 & 21.2 & 3 & 7.7 \\
\hline $500-$ & 15 & 7.4 & 3 & 7.7 \\
\hline No answer & 3 & 1.5 & 2 & 5.1 \\
\hline \multicolumn{5}{|l|}{ 3. Main customer type } \\
\hline Individual & 71 & 35.0 & 31 & 79.5 \\
\hline Company & 64 & 31.5 & 2 & 5.1 \\
\hline National & 48 & 23.6 & 2 & 5.1 \\
\hline others $^{5}$ & 15 & 7.4 & 2 & 5.1 \\
\hline No answer & 5 & 2.5 & 2 & 5.1 \\
\hline
\end{tabular}

(Note 1) Civil engineering work accounts for more than $80 \%$ of total sales. ${ }^{2}$ Civil engineering work accounts for less than $20 \%$ and non-wooden construction work constitutes a greater portion than wooden one. ${ }^{3}$ Civil engineering work accounts for less than $20 \%$ and wooden construction work constitutes a greater portion than non-wooden one. ${ }^{4}$ Each construction type constitutes different portion from 1-3. ${ }^{5}$ Customers account the same share. 
Table 2. Results of Decision Tree by categories (\%)

\begin{tabular}{llll}
\hline Total Number of Instance & 242 (Certified: 39 , Non-certified: 203) & \\
Number of leaves & 7 & & \\
Size of the tree & 10 & & \\
Correctly classified instances & $213(88.02 \%)$ & \\
Kappa statistics & 0.4848 & & \\
Mean absolute error & 0.1919 & & \\
Accuracy of each leave & & Number of classified instances & Correctly cla5ssified instances \\
& Classifies as & 1 & 1 \\
& & $192.23(91.2 \%)$ \\
(1) Check system = no & Non-certified & 210.71 & $18.52(74.05 \%)$ \\
(2) Self-discretion =No.1 & Certified & 25.01 & $2.01(100 \%)$ \\
(3) Self-discretion= No.2 & Non-certified & 2.01 & $2.00(100 \%)$ \\
(4) Customer $=$ Individual & Non-certified & 2.00 & $0.15(100 \%)$ \\
(5) Customer = National & Non-certified & 0.15 & $0.00(-)$ \\
(6) Customer $=$ Mix & Non-certified & 0.00 & $2.00(93.90 \%)$ \\
(7) Customer $=$ Company & Certified & 2.13 & \\
\hline
\end{tabular}

(Note 2) When there are missing values, an instance is divided into some leaves. As a result, the number of instances of each leave becomes decimal.

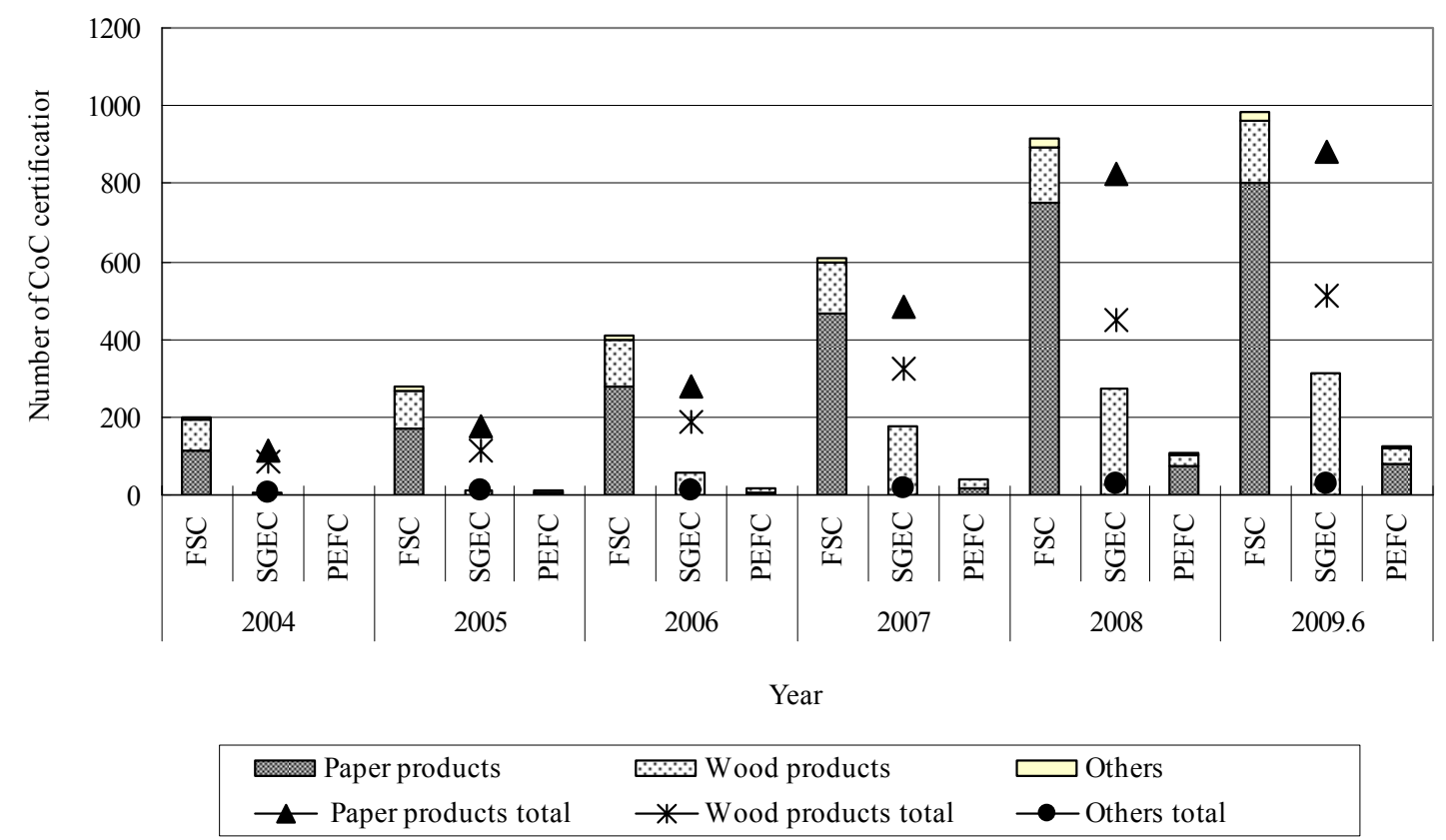

Figure 1. Number and Types of CoC Certification of each scheme provided 


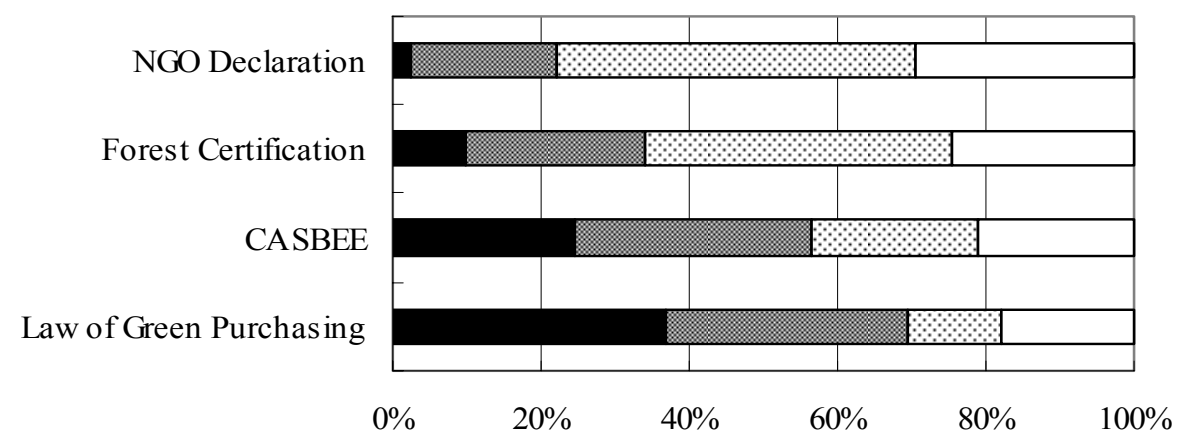

Well know Not know well .

Figure 2. Company's awareness and consciousness on the scheme provided ( $N=203)$

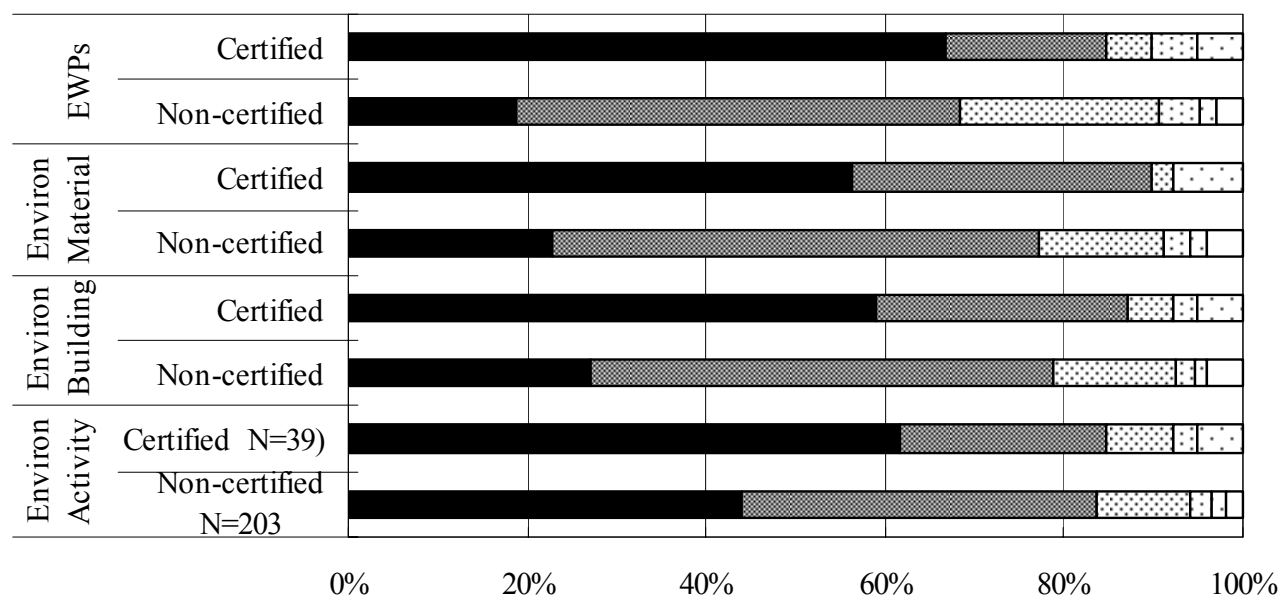

- Very Important

$\square$ Less important
Important to some extent

$\square$ Not important at all

\section{No opinion}

$\square$ No Answer

Figure 3. Recognition on the importance for each activity provided 


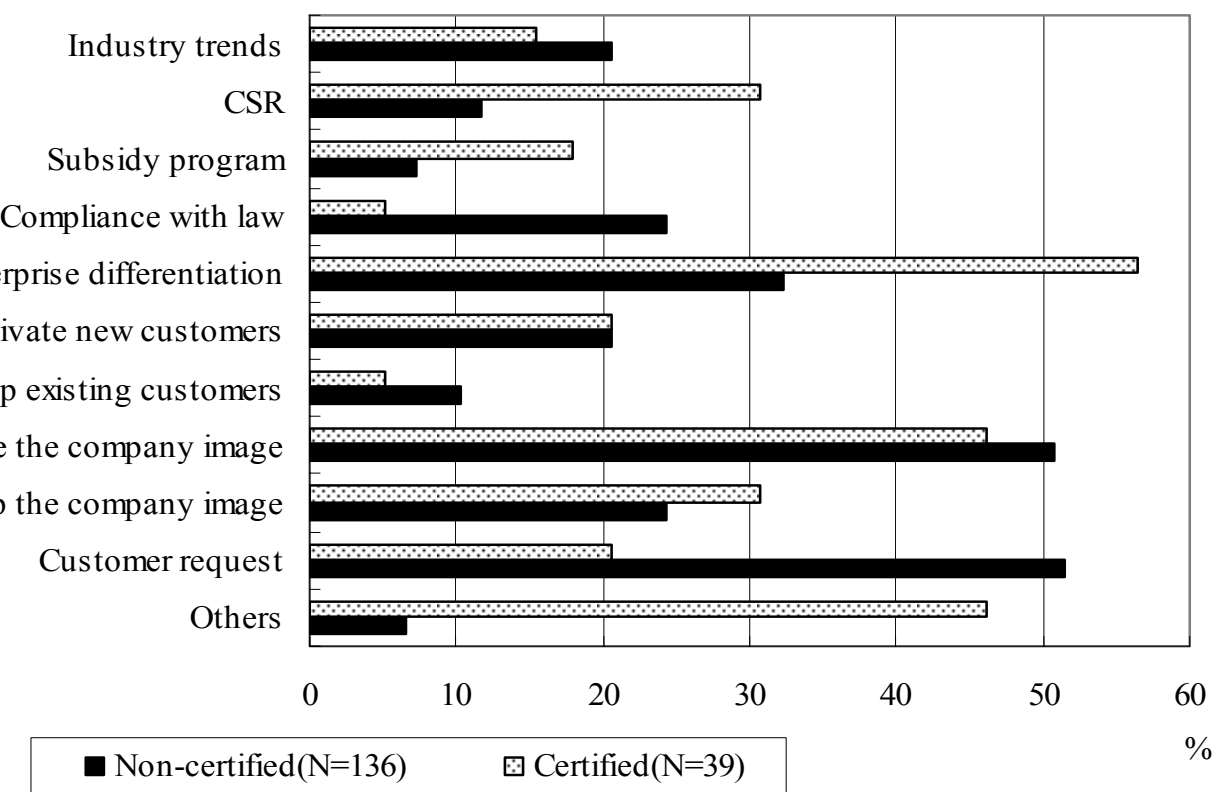

Figure 4. Company's reason on purchasing or intend to purchase of EWPs

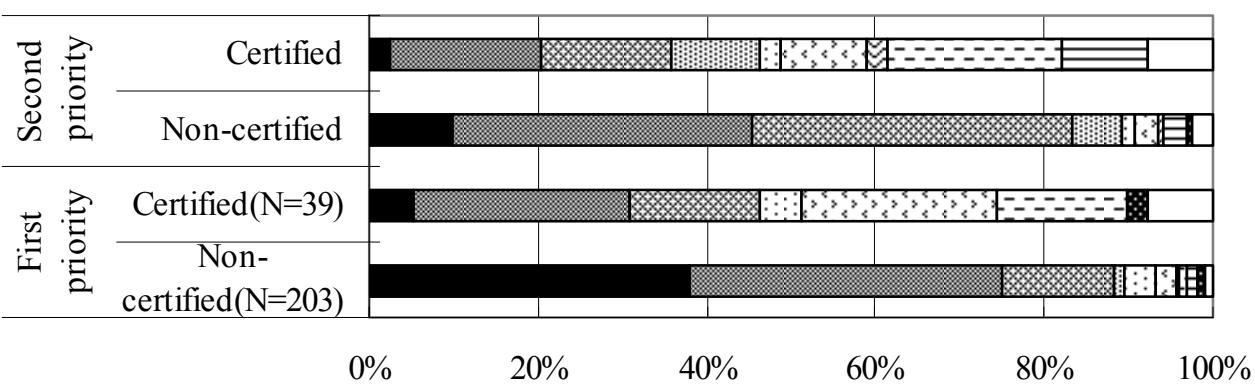

On-specification

용 Availability

종 Responsible supplier

Others

\section{Q Quality}

$\square$ Legality

$\checkmark$ Sustainable forest

$\square$ No answer

\section{图 Price}

$\square$ Domestic

日 Environmental burden

Figure 5. Priorities of wood procurement between certified and non-certified companies 


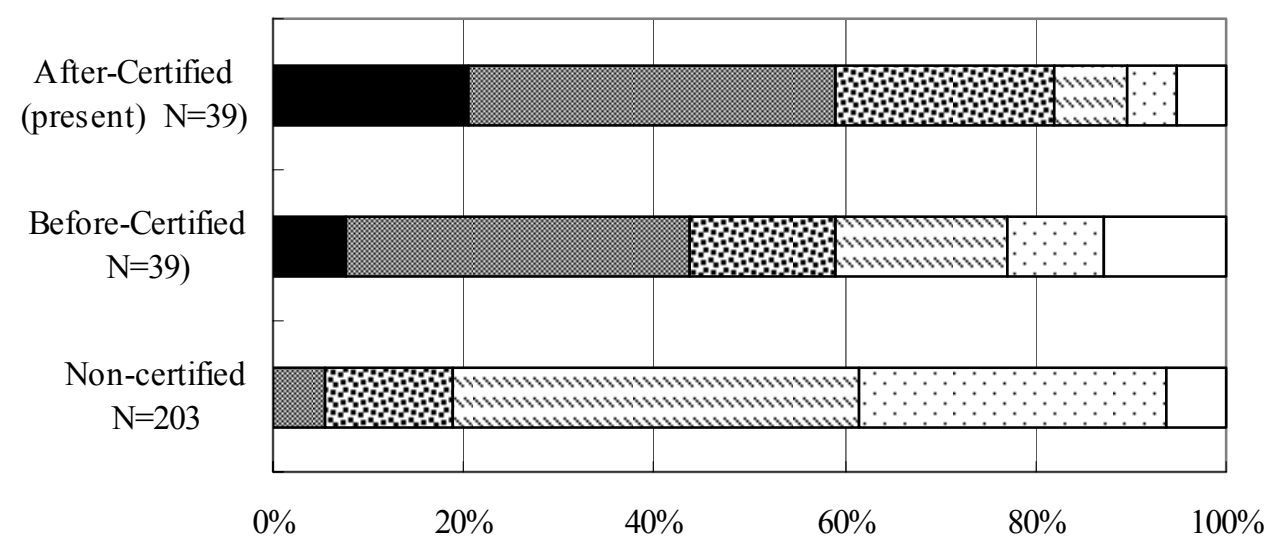

Very well $\square$ Well $₫$ Average $\square$ Poor $\square$ Very poor $\square$ No answer

Figure 6. States of wood supply chain between certified and non-certified companies

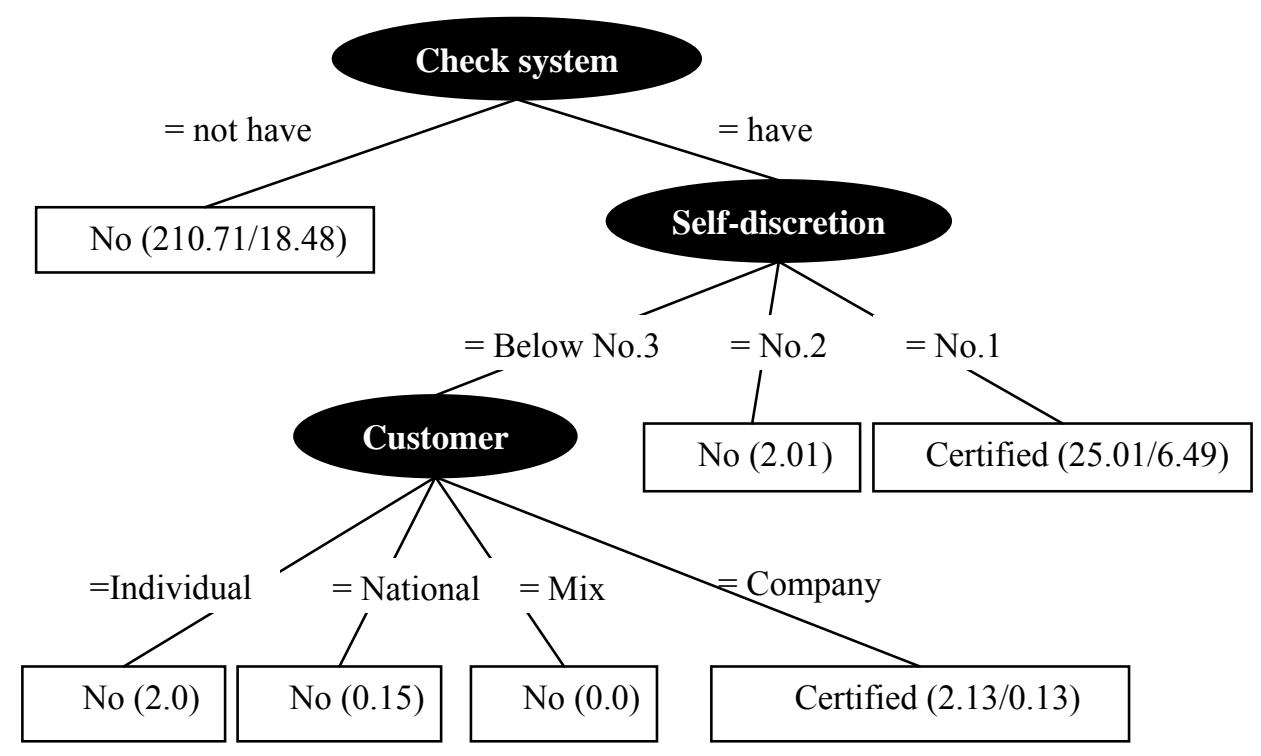

Figure 7. The decision tree of $\mathrm{CoC}$ certification process 